\title{
Cyrano de Bergerac. Les États et Empires de la Lune et du Soleil, sous la direction de Jean-Charles Darmon
}

\section{Daniela Dalla Valle}

\section{(2) OpenEdition}

1 Journals

\section{Edizione digitale}

URL: http://journals.openedition.org/studifrancesi/33112

DOI: 10.4000/studifrancesi.33112

ISSN: 2421-5856

\section{Editore}

Rosenberg \& Sellier

\section{Edizione cartacea}

Data di pubblicazione: 1 décembre 2005

Paginazione: 634

ISSN: 0039-2944

\section{Notizia bibliografica digitale}

Daniela Dalla Valle, «Cyrano de Bergerac. Les États et Empires de la Lune et du Soleil, sous la direction de Jean-Charles Darmon», Studi Francesi [Online], 147 (XLX | III) | 2005, online dal 01 novembre 2015, consultato il 18 avril 2021. URL: http://journals.openedition.org/studifrancesi/33112 ; DOI: https:// doi.org/10.4000/studifrancesi.33112

\section{Questo documento è stato generato automaticamente il 18 avril 2021.}

\section{(c)}

Studi Francesi è distribuita con Licenza Creative Commons Attribuzione - Non commerciale - Non opere derivate 4.0 Internazionale. 


\title{
Cyrano de Bergerac. Les États et Empires de la Lune et du Soleil, sous la direction de Jean-Charles Darmon
}

\author{
Daniela Dalla Valle
}

\section{NOTIZIA}

Cyrano de Bergerac. Les États et Empires de la Lune et du Soleil, sous la direction de JeanCharles Darmon, «Littératures classiques», 53 - Supplément, 2004, pp. 336.

1 Il volume, organizzato da Jean-Charles Darmon, intende puntualizzare il discorso sull'opera narrativa di Cyrano illuminandola da punti di vista diversi, visto che diversi e molteplici sono "les références, les allusions, les sources affichées ou dissimulées, et les interprétations possibles" dell'opera stessa. Jean-Charles Dormon imposta il problema in un'introduzione, Enigmes et défis d'un grand jeu libertin (pp. 5-17). Segue un primo settore di studi - L 'horizon libertin: enjeux polémiques de L'Autre Monde - che comprende cinque articoli: uno di Claudine Poulouin, concentrato sul rapporto fra Cyrano e una serie di episodi della Bibbia, contestati e contrastati ("Dieu avait encore une fois recloué le soleil aux cieux..." Cyrano iconoclaste, pp. 21-38); uno di Isabelle Moreau, che percorre le dimensioni filosofiche con cui il testo cyraniano entra in polemica (Cyrano de Bergerac: les héritages polémiques des Etats et Empires de la Lune et du Soleil, pp. 39-49), mentre Jean-Michel Gros si sofferma sulla Place et fonction du cynisme dans l'œuvre de Cyrano pp. 51-64); Jean-Pierre Cavaillé si concentra sugli «arguments athéistes» del «fils de l'hôte» (forse Chapelle, figlio di François Lhuiller) nell'articolo intitolato "Qu 'il y ait un Dieu.... je vous le nie tout à plat». Contexte théorique et enjeux pratiques des arguments Théistes du Fils de l'hôte (pp. 65-74), mentre Sophie Feller analizza certi attacchi alle credenze del XVII secolo, attuati da Cyrano all'interno di una pratica frequente a tutto il libertinaggio (L'homme affabulateur: anthropologie de la croyance dans L'autre Monde de Cyrano de Bergerac, pp. 75-95). 
2 Il secondo settore del volume raccoglie cinque articoli sotto il titolo generale Entre science et imaginaire: variations ironiques de la fiction. Il primo articolo, di Sylvie Requemora, è dedicato alle macchine volanti e alla loro rappresentazione burlesca, con una serie di curiose illustrazioni (Machines volantes, machine du monde et machinations romanesques dans les Etats et Empires de la Lune et Soleil, pp. 99-114); Dominique Descotes si propone poi di studiare l'esistenza di contatti fra Cyrano e Mersenne (Quelques remarques sur Cyrano et Mersenne, pp. 115-135); Didier Kahn ritorna sul problema dell'alchimia, cercando di puntualizzare su come l'alchimia esisteva in Francia ai tempi di Cyrano, e come Cyrano ne riprende e utilizza alcuni passaggi (L'alchimie dans les Etats et Empires de la Lune et du Soleil, pp. 137-157); Maria Susana Seguin mette a confronto il discorso scientifico e il discorso letterario di Cyrano, «démiurge capable de créer par la seule force de son activité fabulatrice un «autre monde» que la puissance de son imagination rend aussi vrai que celui qu'il a fui dans son voyage imaginaire» (Raison et invention dans Les Etats et Empires de la Lune et du Soleil: $d u$ discours scientifique au discours littéraires, pp. 159-171); e il curatore JeanCharles Darmon completa il settore analizzando determinati contatti tra Cyrano ed alcuni filosofi, come Keplero e Campanella (Rhétorique du songe, fictions heuristiques et politique de la «grimace»: Cyrano sur les traces de Quevedo, de Kepler et de Campanella, pp. 173-208).

3 Infine sei articoli, diversi fra loro come impostazione, compongono la terza parte del volume (Jeux du texte et défis au lecteur: vers une herméneutique «déniaisée»). Passiamo da La question du chou (pp. 211-218) di Georges Molinié, che riprende alcune prospettive di lettura del testo, allo studio di Bérengère Parmentier, che si sofferma sul rapporto tra linguaggio e corpo, in particolare sul "parlare senza lingua", utilizzando altri organi e altri sistemi (Parler sans la langue: Langages et corps dans Les Etats et Empires de Cyrano de Bergerac, pp. 219-236); dall'analisi di Emmanuel Bury, che mette a confronto Cyrano con Luciano (Ménippe dans la lune: Cyrano à l'école de Lucien, pp. 237-252), a quella di Claudine Nédélec, che analizza il rapporto fra l'opera cyraniana e il burlesco (Cyrano et sa "burlesque audace"; dallo studio di Michèle Rosellini, sull'enonciazione alla prima persona ("Mais écoute, Lecteur..." Narration et interlocution dans le double récit de Cyrano" pp. 273-294), alle osservazioni di Madeleine Alcover sull'edizione postuma degli Etats et Empires de la Lune (Statistique et critique d'attribution: l'edition posthume des États et Empires de la Lune, pp. 295-311).

4 Il volume è concluso da una ricca bibliografia. 